\title{
A MATURIDADE DA GESTÃO DE COMPETÊNCIAS
}

O crescente interesse do tema competências no campo de estudos da Administração, longe de ser um mero modismo, alicerçou ao longo dos últimos anos uma consistente e vigorosa produção, por meio de estudos de natureza conceitual - associados a diferentes campos do conhecimento - e pela explanação das experiências organizacionais em sua aplicabilidade prática. De forma a identificar contribuições que venham a ser relevantes aos leitores, as sugestões abaixo, feitas pelo professor Allan Claudius Queiroz Barbosa, professor da UFMG e coordenador do Nig.one e do Observatório de Recursos Humanos em Saúde, ajudam no entendimento do tema e na sua aplicabilidade prática.
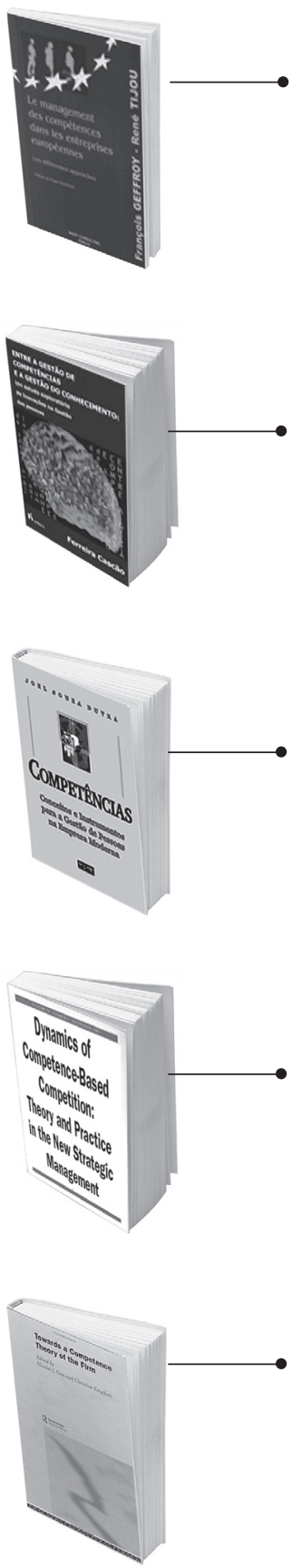

LE MANAGEMENT DES COMPÉTENCES DANS LES ENTREPRISES EUROPÉENNES. François Geffroy e René Tijou. Paris: Insep Consulting Editions, 2002. 166 p.

Resultado de pesquisa conduzida pela European Training and Development Federation (ETDF) em 30 empresas da Europa (França, Suíça, Itália, Inglaterra e Irlanda), apresenta discussão sobre competências e sua conceitualização, o contexto das políticas e as práticas de gestão associadas. Observa que a noção de competências não tem o mesmo significado nos diferentes países, sendo pautada em princípios variados. É um conceito dinâmico e diverso, sugerindo que a função recursos humanos ocupe posição privilegiada no contexto da gestão de competências.

\section{ENTRE A GESTÃO DE COMPETÊNCIAS E A GESTÃO DO CONHECIMENTO: um estudo exploratório de inovações} na gestão de pessoas. Ferreira Cascão. Lisboa: Editora RH, 2004. 414 p.

O autor, docente em Lisboa, realiza amplo estudo em quatro grandes organizações (Portugal Telecom, SmithKline Beecham, ICL e Siemens). Por meio de cuidadoso relato metodológico dos casos, analisa a adoção de modelos pautados em competências e sua ligação com as práticas de recursos humanos. Constata a emergência, ainda que de maneira implícita, de processos de gestão (leia-se gestão do conhecimento), e observa os mecanismos de adoção bem como as dificuldades decorrentes, propondo maior integração na relação entre recursos humanos e competências.

COMPETÊNCIAS: conceitos e instrumentos para a gestão de pessoas na empresa moderna. Joel Souza Dutra. São Paulo: Editora Atlas, 2004. 206 p.

O autor aborda questões que perpassam a temática das competências em sua interligação com a gestão de recursos humanos. Faz uma breve revisão do conceito, partindo de McClelland e Boyatziz, e propõe uma abordagem pautada na entrega e agregação de valor da pessoa à organização. Ao articular competências aos conceitos de complexidade e espaço ocupacional para o entendimento da gestão de pessoas, formula um modelo estratégico e integrado com base em estudos desenvolvidos em empresas brasileiras e apresenta sua aplicação no setor petroquímico.

DYNAMICS OF COMPETENCE-BASED COMPETITION: Theory and Practice in the New Strategic Management. Ron Sanchez, Aimé Heene e Howard Thomaz (Eds.). Oxford: Elsevier Science Ltd. 1996. 403 p.

O trabalho joga luz sobre uma das dimensões teóricas possíveis no trato das competências, ao abordar sua aplicação em uma variedade de contextos competitivos. Tem como inspiração os escritos de C. K. Prahalad e Gary Hamel e propõe-se constituir uma fundamentação teórica para a perspectiva das competências, buscando maior interface com a gestão estratégica. Dividido em cinco partes e contendo 16 artigos, mescla contribuições de natureza conceitual, em que é possível enxergar alicerces teóricos que sustentam os argumentos propostos, e sua aplicabilidade em diferentes segmentos produtivos.

TOWARDS A COMPETENCE THEORY OF THE FIRM. Nicolai Foss e Christian Knudsen (Eds.). London: Routledge, 1996. 205 p.

A obra representa uma importante contribuição à perspectiva das competências, concentrando-se no plano estratégico, mas ressaltando a marcante colaboração do estudo de Richard Nelson e Sidney Winter, de 1982, a partir da formulação de sua teoria evolucionária da firma. Pautada pela construção de uma agenda comum que oriente a reflexão, tem como uma de suas premissas a perspectiva de que as competências são estratégicas, consideradas a partir da descoberta das fontes de vantagens competitivas. 